\title{
Photoelectrochemical Hydrogen Production on Textured Silicon Photocathode
}

\author{
Ilwhan $\mathrm{Oh}^{*}$ \\ Korea Advanced Nanofabrication Center, Suwon, Gyeonggi 444-270
}

(Received October 19, 2011 : Accepted October 24, 2011)

\begin{abstract}
Wet chemical etching methods were utilized to conduct Si surface texturing, which could enhance photoelectrochemical hydrogen generation rate. Two different etching methods tested, which were anisotropic metal-catalyzed electroless etching and isotropic etching. The $\mathrm{Si}$ nano-texture that was fabricated by the anisotropic etching showed $\sim 25 \%$ increase in photocurrent for $\mathrm{H} 2$ generation. The photocurrent enhancement was attributed to the reduced reflection loss at the nano-textured $\mathrm{Si}$ surface, which provided a layer of intermediate density between water and the $\mathrm{Si}$ substrate.
\end{abstract}

Keywords : Silicon texturing, Metal-catalyzed electroless etching, Photoelectrochemistry, Hydrogen evolution reaction, Solar water splitting

\section{Introduction}

Recently a renewed interest has been shown in solar water splitting as a potential solution to provide emissionfree clean hydrogen fuel for transportation and other energy applications. ${ }^{1)}$ Photoelectrochemical hydrogen production at the semiconductor/electrolyte interface has been studied for decades. ${ }^{2-4)}$ In solar fuel production, a photoelectrochemical cell converts photon energy into chemical energy and generates $\mathrm{H}_{2}$ on cathode and $\mathrm{O}_{2}$ on anode, as described in the following half-cell reactions:

$$
\begin{aligned}
& 2 \mathrm{H}^{+}+2 \mathrm{e}^{-} \rightarrow \mathrm{H}_{2} \text { (cathode) } \\
& \mathrm{H}_{2} \mathrm{O} \rightarrow 1 / 2 \mathrm{O}_{2}+2 \mathrm{H}^{+}+2 \mathrm{e}^{-} \text {(anode) }
\end{aligned}
$$

The Gibbs free energy change $\Delta G^{\mathrm{o}}$ of the net reaction is $237 \mathrm{~kJ} / \mathrm{mol}$, or equivalently, the standard emf $\Delta E^{\mathrm{o}}$ is $-1.23 \mathrm{~V}$. As the negative emf indicates, the net reaction is energetically uphill reaction.

Silicon is earth-abundant, relatively low-cost semiconductor material that is most widely used in current photovoltaics, with vast knowledge base and infrastructure. ${ }^{5)}$ The photoelectrochemical $\mathrm{H}_{2}$ generation at the

*E-mail: ioh0204@gmail.com
Si/electrolyte interface has been studied for decades. ${ }^{6-10)}$ Compared to the solid-state solar conversion devices, one of the disadvantages of the solar energy conversion devices based on semiconductor/electrolyte interface is that it very difficult or impossible to introduce antireflection layer (e.g., $\mathrm{SiO}_{2}$ and/or $\mathrm{Si}_{\mathrm{x}} \mathrm{N}_{\mathrm{y}}$ coating on top of the p-n junction in the conventional $\mathrm{Si}$ solar cells), because such layer will easily block the electron transfer at the semiconductor/electrolyte interface. As depicted in Fig. 1, due to the large difference in the refractive indices of $\mathrm{Si}(\mathrm{n}=3.5)$ and electrolyte $(\mathrm{n}=1.3)$, the planar $\mathrm{Si} /$ electrolyte interface reflects as much as $25 \%$ of the incident visible light. ${ }^{11)}$ Alternative approach to reduce
A

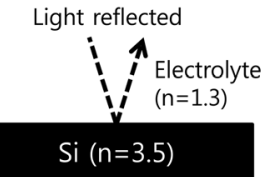

B Reduced reflection
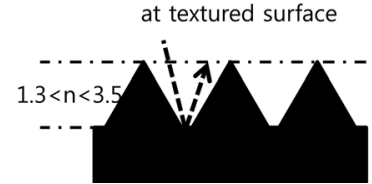

Fig. 1. (A) Schematic showing reflection loss at the semiconductor/electrolyte interface which has a large difference in refractive indexes values (n). (B) Surface texturing can reduce reflection at the semiconductor/electrolyte interface by providing an anti-reflection layer with intermediate density between water and the $\mathrm{Si}$ substrate. 
the reflection loss is Si surface texturing. Surface texturing usually refers to introducing micrometer or even nanometer scale embossing structures on the Si surface, which effectively reduces reflection loss of incident photon thus enhances generated photocurrent. ${ }^{12-14)}$ Fabrication methods for the $\mathrm{Si}$ surface texturing includes alkaline etch, acid etch, and reactive ion etch (RIE). The RIE method requires expensive and cumbersome ultra-high vacuum equipments. On the other hand, wet chemical processes provide a simple, rapid, and effective route to low-reflectance $\mathrm{Si}$ surface texturing. Among several different wet etch systems, the $\mathrm{HF} / \mathrm{HNO}_{3}$ system is the most commonly used low-temperature process. In spite of the direct benefit that can be obtained from the surface texturing, adoption of the surface texturing into the semiconductor/electrolyte interface has been rarely investigated. ${ }^{11)}$

Here in this work, we utilized two different roomtemperature wet etch methods for $\mathrm{Si}$ surface texturing: the $\mathrm{HF} / \mathrm{HNO}_{3}$ system and the metal-catalyzed $\mathrm{HF}$ etching. Optical and electron microscopy measurements showed that the wet etch methods effectively produced micrometer- or nanometer-sized pits/pores or grooves on the Si surface. The textured $\mathrm{Si}$ surface was evaluated by measuring the photoelectrochemical $\mathrm{H}_{2}$ generation. Effect of the surface texturing on the magnitude of photocurrent was examined and discussed.

\section{Experimental}

\subsection{Wet chemical texturing of crystalline $\mathrm{Si}$}

A p-type Si (100) wafer (Wafer World, Inc.; $10 \mathrm{ohm-}$ $\mathrm{cm}$; B-doped) was degreased by rinsing with acetone, isopropyl alcohol, and ultrapure deionized water (DIW) in sequence. The $\mathrm{Si}$ surface was further cleaned by immersing in piranha $\left(1: 3 \mathrm{H}_{2} \mathrm{O}_{2}+\mathrm{H}_{2} \mathrm{SO}_{4}\right)$ for $3 \mathrm{~min}$ and in $1: 10 \mathrm{HF}$ for $2 \mathrm{~min}$ to remove surface oxide. Backside ohmic contact was formed by depositing and annealing an ohmic metal layer onto the HF-treated $\mathrm{Si}$ wafer. For metal-catalyzed electroless etching, the $\mathrm{Si}$ sample was immersed in $8 \mathrm{mM} \mathrm{AgNO}_{3}$ and $4.6 \mathrm{M} \mathrm{HF}$ for a designated duration of time, then transferred to diluted $\mathrm{HNO}_{3}$ to remove dendritic $\mathrm{Ag}$ residue. For isotropic etching, the cleaned $\mathrm{Si}$ sample was immersed in a $1: 1(\mathrm{v} / \mathrm{v})$ mixture of $60 \% \mathrm{HNO}_{3}$ and $50 \% \mathrm{HF}$ for a designated duration of time, then thoroughly rinsed with deionized water.

\subsection{Photoelectrochemical $\mathbf{H}_{2}$ generation measure-} ments

For photoelectrochemical measurements, a O-ring sealed Teflon cell was used that could accommodate a three-electrode configuration and secure a light path to the Si/electrolyte interface. Backside ohmic metal was electrically connected to a $\mathrm{Cu}$ metal foil. The front side of the Si sample was firmly pressed and sealed with a Teflon O-ring, by which the projected electrode area was defined. $\left(0.286 \mathrm{~cm}^{2}\right)$ A Pt counter electrode and a standard calomel reference electrode (SCE) were used. For illumination source, a halogen lamp was used, the intensity of which was controlled by the distance between the lamp and the photoelectrochemical cell. A Si photodiode (Hamamatus; model S2386-18K) was used for intensity calibration. All glassware was thoroughly cleaned in an oxidizing bath (Nochromix, Godax Laboratories, Inc.) and rinsed with ultrapure water prior to use. Electrolyte solution was prepared by adding concentrated $\mathrm{H}_{2} \mathrm{SO}_{4}$ (Aldrich) into $0.5 \mathrm{M} \mathrm{K}_{2} \mathrm{SO}_{4}$ along with $\mathrm{pH}$ measurement. All chemicals were used as received. All measurements were conducted in threeelectrode configuration using a $\mathrm{CHI} 660 \mathrm{D}$ potentiostat.

\section{Results and Discussion}

Fig. 2 shows SEM micrographs of the textured $\mathrm{Si}$, which was fabricated by metal-catalyzed electroless etching (MCEE) of bulk crystalline p-type (100)-Si (10 W-cm; B-doped) in $8 \mathrm{mM} \mathrm{AgNO}_{3}$ and $4.6 \mathrm{M} \mathrm{HF}$ for $6 \mathrm{~min}$. In the MCEE method, oxidizing agent $\mathrm{Ag}^{+}$ in current work) provides holes that are needed to oxidize $\mathrm{Si}$ atoms and, at the same time, HF etches away $\mathrm{Si}$ atoms. ${ }^{15-20)}$ Etchant composition of the MCEE method

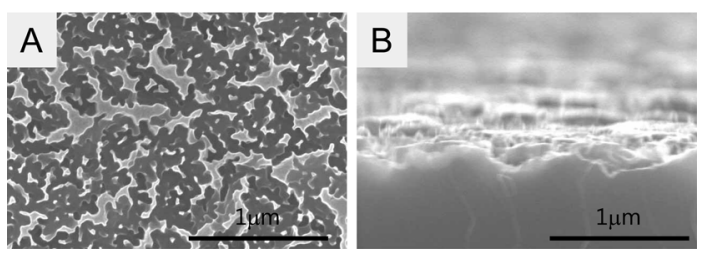

Fig. 2. Scanning electron micrographs of the surface nanotextured $\mathrm{Si}$, which was fabricated by metal-catalyzed electroless etching (MCEE) of bulk crystalline p-type (100)-Si (10 W$\mathrm{cm}$; B-doped) in $8 \mathrm{mM} \mathrm{AgNO}$ and $4.6 \mathrm{M} \mathrm{HF}$ for $6 \mathrm{~min}$. (A) Top view of the nano-textured Si surface showing. (B) Profile view of the nano-textured Si layer. 
is similar to the traditional $\mathrm{Si}$ etchants in the sense that both oxidizing agent and $\mathrm{HF}$ are present. However, $\mathrm{Ag}^{+}$ is reduced to form nanostructured deposit on the $\mathrm{Si}$ surface, which functions as nanostructured template in the further etching of the underlying $\mathrm{Si}$. As shown in Fig. 2(A), the Si surface textured through the MCEE method exhibits nano-texture that ranges from 50 to $200 \mathrm{~nm}$ in lateral dimension. Cross-sectional image in Fig. 2(B) shows that the vertical dimension of the nanotexture is $\sim 200 \mathrm{~nm}$. The vertical dimension is increased in proportion to etch time. Because the dimension of the nano-texture is comparable to the wavelength of visible light, the nano-textured surface effectively suppresses light reflection at the surface, which is evidenced by 'black' surface color with low reflection as compared to mirror-like surface of polished planar Si.

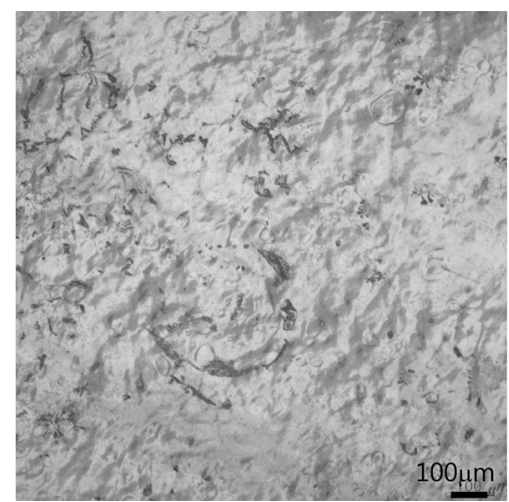

Fig. 3. Optical microscope image the Si surface, which was textured by isotropic etching of crystalline p-type $\mathrm{Si}(100)$ (resistivity $\sim 10 \mathrm{~W}-\mathrm{cm}$; B-doped) in a $1: 1(\mathrm{v} / \mathrm{v})$ mixture of $60 \% \mathrm{HNO}_{3}$ and $50 \% \mathrm{HF}$ for 10 sec.
Fig. 3 shows an optical microscope image of the $\mathrm{Si}$ surface, which was textured by isotropic etching of the same crystalline $\mathrm{Si}$ in a $1: 1(\mathrm{v} / \mathrm{v})$ mixture of $60 \%$ $\mathrm{HNO}_{3}$ and $50 \% \mathrm{HF}$ for $10 \mathrm{sec}$.

The $\mathrm{HNO}_{3} / \mathrm{HF}$ etch system is the most commonly used isotropic $\mathrm{Si}$ etchant composition. Because the $\mathrm{HNO}_{3} /$ $\mathrm{HF}$ etch system is an isotropic etchant, the image in Fig. 3 exhibits macroscopic grooves tens of microns in lateral dimension, in contrast to the nano-textured features produced by the MCEE method in Fig. 2.

Fig. 4 shows photoelectrochemical measurements of the $\mathrm{Si}$ photocathodes, which were textured by the MCEE method, in acidic solution of $\mathrm{H}_{2} \mathrm{SO}_{4}+0.5 \mathrm{M}$ $\mathrm{K}_{2} \mathrm{SO}_{4}$ ( $\mathrm{pH}$ 1). During the measurements, the textured Si photocathode was constantly illuminated with simulated sunlight (intensity $=16 \mathrm{~mW} / \mathrm{cm}^{2}$ ). When the Si photocathode absorbs a photon, a minority carrier (electron in case of p-type $\mathrm{Si}$ ) is generated and flows toward the semiconductor/electrolyte interface, where the minority carrier is transferred across the semiconductor/electrolyte interface, reducing $\mathrm{H}^{+}$to $\mathrm{H}_{2}$. Fig. 4(A) shows the current density $(J)$-electrode potential $(E)$ measurements on the textured $\mathrm{Si}$ photocathode. When $E$ is more positive of $0.2 \mathrm{~V}$, the value of $J$ is virtually zero and $\mathrm{H}_{2}$ is not produced. As $E$ is scanned in negative direction, the current increases and, at the potential regime more negative of $-0.2 \mathrm{~V}$, reaches a limiting photocurrent that is determined mainly by the transmitted photon intensity. The sigmoidal $J-E$ graph is typical of photon-limited photoelectrochemical response. In Fig. 4(A), the MCEEtextured Si photocathodes exhibits enhanced photocurrent compared to the planar $\mathrm{Si}$. This result indicates that,
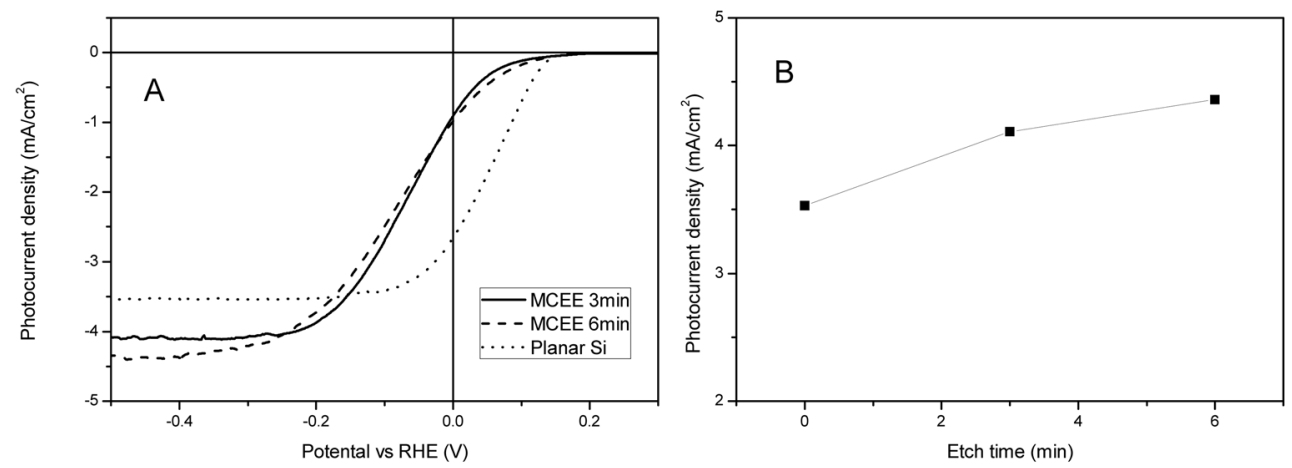

Fig. 4. (A) Photoelectrochemical $\mathrm{H}_{2}$ generation on MCEE Si photocathode in a solution of $\mathrm{H}_{2} \mathrm{SO}_{4}+0.5 \mathrm{M} \mathrm{K}_{2} \mathrm{SO}_{4}(\mathrm{pH} 1)$ with simulated solar radiation (intensity $=16 \mathrm{~mW} / \mathrm{cm}^{2}$ ). The $\mathrm{Si}$ surface is textured by metal-catalyzed electroless etching in $8 \mathrm{mM}$ $\mathrm{AgNO}_{3}$ and 4.6M HF for a designated time (B) Relationship between limiting photocurrent and electroless etch time. 

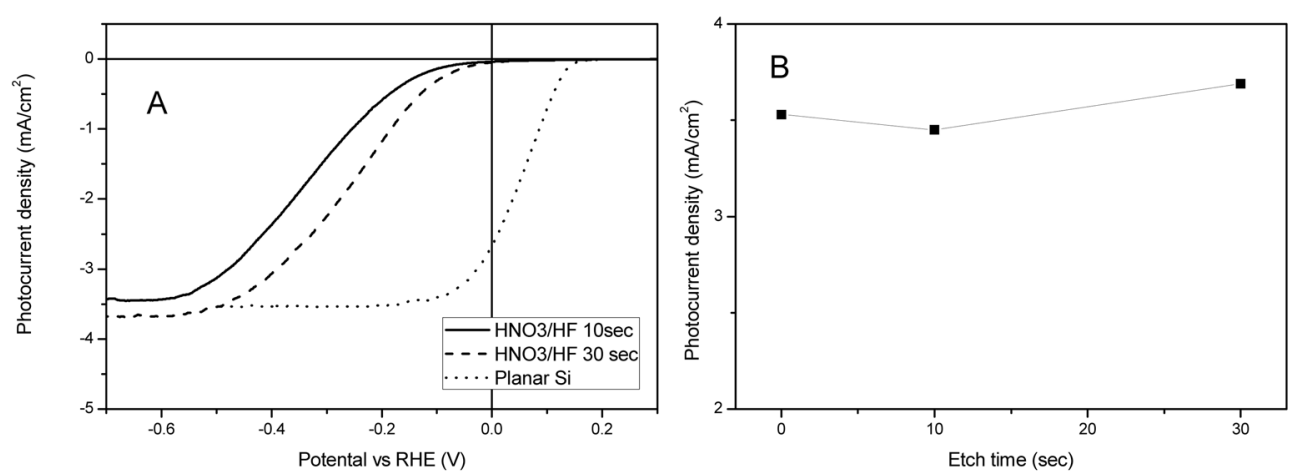

Fig. 5. (A) Photoelectrochemical $\mathrm{H}_{2}$ generation on $\mathrm{Si}$ photocathode in a solution of $\mathrm{H}_{2} \mathrm{SO}_{4}+0.5 \mathrm{M} \mathrm{K}_{2} \mathrm{SO}_{4}$ (pH 1) with simulated solar radiation (intensity $=16 \mathrm{~mW} / \mathrm{cm}^{2}$ ). The $\mathrm{Si}$ surface is textured by isotropic etching in a $1: 1(\mathrm{v} / \mathrm{v})$ mixture of $60 \% \mathrm{HNO}_{3}$ and $50 \% \mathrm{HF}$ for a designated time (B) Relationship between limiting photocurrent and etch time.

while substantial amount of incident photon is reflected at the mirror-like planar $\mathrm{Si}$ interface, the textured $\mathrm{Si}$ surface significantly reduces reflection loss and generates larger current. Fig. 4(B) shows the effect of etch time on the limiting photocurrent density. Compared to the planar $\mathrm{Si}$ (etch time $=0 \mathrm{~min}$ ), the 6-min electroless etched Si photocathode shows as large as $24 \%$ increase in photocurrent. Previous report indicates that, at the mirror-like planar Si/electrolyte interface, as large as $25 \%$ of the incident solar radiation is reflected. ${ }^{11)}$ On the other hand, the nano-textured $\mathrm{Si}$ surface provides an antireflection layer with intermediate density and refractive index between water and the $\mathrm{Si}$ substrate, dramatically reducing reflection at the $\mathrm{Si}$ interface.

Fig. 5 shows photoelectrochemical measurements of the $\mathrm{Si}$ photocathodes, which were textured by the $\mathrm{HNO}_{3} /$ $\mathrm{HF}$ isotropic etchant, in acidic solution of $\mathrm{H}_{2} \mathrm{SO}_{4}+0.5 \mathrm{M}$ $\mathrm{K}_{2} \mathrm{SO}_{4}$ (pH 1) illuminated with simulated sunlight (intensity $=16 \mathrm{~mW} / \mathrm{cm}^{2}$ ). Comparison of limiting photocurrents indicates that the isotropic etching of $\mathrm{Si}$ provides little enhancement. This result indicates that the macroscopic grooving produced from the isotropic etching, as observed in Fig. 3, is not very effective in reducing light reflection from the $\mathrm{Si}$ surface. Furthermore, after the isotropic etching, the photovoltage is significantly reduced, indicating formation of passivation layer or change of surface chemistry at the etched Si surface.

\section{Conclusion}

Two different wet chemical etching methods were evaluate for $\mathrm{Si}$ surface texturing to reduce reflection loss at the Si/electrolyte interface: the anisotropic etching assisted by metal ion and the isotropic etching in the $\mathrm{HNO}_{3} / \mathrm{HF}$ system. Optical and electron microscopy measurements verifies that the MCEE method produces a nano-textured surface that functions as effective antireflection layer by providing intermediate density layer between water and the $\mathrm{Si}$ substrate, while the isotropic etching produces macroscopic grooves on the $\mathrm{Si}$ surface. Photoelectrochemical $\mathrm{H}_{2}$ generation measurements showed that the anisotropic etched $\mathrm{Si}$ photocathode exhibited $\sim 25 \%$ enhancement in photocurrent, which was attributed to reduced light reflection at the nano-textured $\mathrm{Si}$ interface.

\section{References}

1. J. A. Turner, 'Sustainable Hydrogen Production', Science, 305, 972, (2004).

2. A. Heller, 'Conversion of sunlight into electrical power and photoassisted electrolysis of water in photoelectrochemical cells', Acc. Chem. Res., 14, 154, (1981).

3. M. G. Walter, E. L. Warren, J. R. McKone, S. W. Boettcher, Q. Mi, E. A. Santori, and N. S. Lewis, 'Solar Water Splitting Cells', Chem. Rev., 110, 6446, (2010).

4. A. J. Bard and M. A. Fox, 'Artificial Photosynthesis: Solar Splitting of Water to Hydrogen and Oxygen', Acc. Chem. Res., 28, 141, (1995).

5. A. Luque and S. Hegedus, Eds., Handbook of photovoltaic science and engineering, John Wiley \& Sons, West Sussex, (2003).

6. D. C. Bookbinder, N. S. Lewis, M. G. Bradley, A. B. Bocarsly, and M. S. Wrighton, 'Photoelectrochemical reduction of $\mathrm{N}, \mathrm{N}^{\prime}$-dimethyl-4,4' -bipyridinium in aqueous 
media at p-type silicon: sustained photogeneration of a species capable of evolving hydrogen', J. Am. Chem. Soc., 101, 7721, (1979).

7. A. B. Bocarsly, D. C. Bookbinder, R. N. Dominey, N. S. Lewis, and M. S. Wrighton, 'Photoreduction at illuminated p-type semiconducting silicon photoelectrodes. Evidence for fermi level pinning', J. Am. Chem. Soc., 102, 3683, (1980).

8. D. C. Bookbinder, J. A. Bruce, R. N. Dominey, N. S. Lewis, and M. S. Wrighton, 'Synthesis and characterization of a photosensitive interface for hydrogen generation: Chemically modified p-type semiconducting photocathodes', Proc. Nat. Acad. Sci., 77, 6280, (1980).

9. Y. Nakato, Y. Egi, M. Hiramoto, and H. Tsubomura, 'Hydrogen evolution and iodine reduction on an illuminated n-p junction silicon electrode and its application to efficient solar photoelectrolysis of hydrogen iodide', J. Phys. Chem., 88, 4218, (1984).

10. S. W. Boettcher, J. M. Spurgeon, M. C. Putnam, E. L. Warren, D. B. Turner-Evans, M. D. Kelzenberg, J. R. Maiolo, H. A. Atwater, and N. S. Lewis, 'Energyconversion properties of vapor-liquid-solid-grown silicon wire-array photocathodes', Science, 327, 185, (2010).

11. J. Oh, T. G. Deutsch, H.-C. Yuan, and H. M. Branz, 'Nanoporous black silicon photocathode for $\mathrm{H} 2$ production by photoelectrochemical water splitting', Ener. Env. Sci., 4, 1690, (2011)

12. P. Campbell and M. A. Green, 'Light trapping properties of pyramidally textured surfaces', J. App. Phys., 62, 243, (1987).

13. B. Gonzalez-Diaz, R. Guerrero-Lemus, B. Diaz-Herrera,
N. Marrero, J. Mendez-Ramos, and D. Borchert, 'Optimization of roughness, reflectance and photoluminescence for acid textured mc-Si solar cells etched at different $\mathrm{HF} / \mathrm{HNO}_{3}$ concentrations', Mat. Sci. Eng.: B, 159-160, 295, (2009).

14. K. Kim, S. K. Dhungel, S. Jung, D. Mangalaraj, and J. Yi, 'Texturing of large area multi-crystalline silicon wafers through different chemical approaches for solar cell fabrication', Sol. Ener. Mat. Sol. Cells, 92, 960, (2008).

15. A. I. Hochbaum, R. Chen, R. D. Delgado, W. Liang, E. C. Garnett, M. Najarian, A. Majumdar, and P. Yang, 'Enhanced thermoelectric performance of rough silicon nanowires', Nature, 451, 163, (2008).

16. A. I. Hochbaum, D. Gargas, Y. J. Hwang, and P. Yang, 'Single Crystalline Mesoporous Silicon Nanowires', Nano Lett., 9, 3550, (2009).

17. K.-Q. Peng, Y.-J. Yan, S.-P. Gao, and J. Zhu, 'Synthesis of Large-Area Silicon Nanowire Arrays via Self-Assembling Nanoelectrochemistry', Adv. Mat., 14, 1164, (2002).

18. Y. Qu, L. Liao, Y. Li, H. Zhang, Y. Huang, and X. Duan, 'Electrically Conductive and Optically Active Porous Silicon Nanowires', Nano Lett., 9, 4539, (2009).

19. M.-L. Zhang, K.-Q. Peng, X. Fan, J.-S. Jie, R.-Q. Zhang, S.-T. Lee, and N.-B. Wong, 'Preparation of Large-Area Uniform Silicon Nanowires Arrays through Metal-Assisted Chemical Etching', J.Phys. Chem. C, 112, 4444, (2008).

20. X. Zhong, Y. Qu, Y.-C. Lin, L. Liao, and X. Duan, 'Unveiling the Formation Pathway of Single Crystalline Porous Silicon Nanowires', ACS App. Mat. Inter, 3, 261, (2011). 